\title{
Assessing the film-substrate interaction in germania films on reconstructed $\mathrm{Au}(111)$
}

\author{
A. L. Lewandowski, ${ }^{1}$ F. Stavale $\odot,{ }^{2}$ S. Tosoni, ${ }^{3}$ W.-D. Schneider $\odot,{ }^{1}$ M. Heyde $\odot,{ }^{1},{ }^{*}$ G. Pacchioni, ${ }^{3}$ and H.-J. Freund ${ }^{1}$ \\ ${ }^{1}$ Fritz-Haber-Institut der Max-Planck-Gesellschaft, Faradayweg 4-6, 14195 Berlin, Germany \\ ${ }^{2}$ Centro Brasileiro de Pesquisas Físicas, 22290-180 Rio de Janeiro, RJ, Brazil \\ ${ }^{3}$ Department of Materials Science, Università di Milano-Bicocca, Via R. Cozzi 55, Milan, Italy
}

(Received 3 September 2019; revised manuscript received 14 October 2019; published 6 December 2019)

\begin{abstract}
Purely amorphous germania bilayer films are grown on a reconstructed $\mathrm{Au}(111)$ surface. The presence of the film affects the native configuration of the Au soliton walls, as observed with scanning tunneling microscopy. They partly avoid the film islands, and partly penetrate under film patches. This behavior indicates a weaker filmsubstrate interaction than the one reported for other oxide films on reconstructed $\mathrm{Au}(111)$. Moreover, this new system highlights the impact of the metal support on the structure of ultrathin films of germania: With decreasing film-substrate interaction the amorphous phase is promoted. Density functional theory calculations confirm and rationalize the experimental observations. This work provides a useful generalization of the relationship between film structure and adhesion energy.
\end{abstract}

DOI: 10.1103/PhysRevB.100.241403

The $\mathrm{Au}(111)$ reconstructed surface has been widely used in surface science adsorption studies. The main reason for that is its combination of interesting properties ruled by its chemical inertness, high electronegativity, and large reconstruction. Concerning the latter, the surface reconstructs with a $(22 \times \sqrt{3})$ periodicity with the presence of an additional gold atom in the [11̄0] direction of the topmost layer [1-4]. This leads to two stacking domains, the hexagonal close packed (hcp) and the face centered cubic (fcc), which rotate periodically $120^{\circ}$ forming its well-known "herringbone" pattern. This surface termination serves as a nonreactive template for molecules and nanostructures [5]. The soliton walls that separate both domains are typically seen with a scanning tunneling microscope (STM) as bright parallel paired rows, as shown in Fig. 2(a) [6,7].

As the STM can easily sense any perturbation in the herringbone reconstruction, many organic-metal interface studies have been carried out on reconstructed $\mathrm{Au}(111)$. Three interaction regimes between organic molecules and the $\mathrm{Au}(111)$ surface have been summarized by Iski et al. [8]. Aromatic molecules tend to couple weakly to the substrate leaving the herringbone reconstruction unaltered [9-15]. In contrast, some adsorbates, typically oxygen or sulfur containing molecules, interact so strongly with the metal surface that they may extract gold atoms [16-21]. An intermediate behavior happens when the adsorbates alter the herringbone reconstruction, but depending on the coverage and annealing treatment may not lift the reconstruction completely [8,21-29].

\section{*heyde@fhi-berlin.mpg.de}

Published by the American Physical Society under the terms of the Creative Commons Attribution 4.0 International license. Further distribution of this work must maintain attribution to the author(s) and the published article's title, journal citation, and DOI.
In the field of ultrathin oxide films, $\mathrm{Au}(111)$ represents also an interesting metal substrate [30]. Oxide films, such as $\mathrm{MgO}$ [31], $\mathrm{TiO}_{2}$ [32,33], $\mathrm{ZnO}$ [34], and $\mathrm{MoO}_{3}$ [35] lift the herringbone reconstruction. This effect is often detected in submonolayer films by STM. In contrast, graphene and $\mathrm{NaCl}$ films on $\mathrm{Au}(111)$ do not affect the herringbone reconstruction [36-38]. The germanium dioxide films supported on $\mathrm{Au}(111)$ presented here display an interaction that is intermediate between weakly interacting systems $(\mathrm{NaCl}$ and graphene) and oxide films that lift the Au reconstruction completely.

Here we report the successful preparation and characterization of germania bilayer films on a reconstructed $\mathrm{Au}(111)$ $(22 \times \sqrt{3})$ surface. The strength of the film-substrate interaction is qualitatively estimated from the change of the herringbone reconstruction observed in STM and quantitatively determined by density functional theory (DFT) calculations.

The preparation procedure of the films follows the steps reported previously for germania films supported on $\mathrm{Ru}(0001)$ and $\mathrm{Pt}(111)$ [39-41]. The $\mathrm{Au}(111)$ single crystal surface is cleaned by several cycles of sputtering and annealing at $820 \mathrm{~K}$ for $15 \mathrm{~min}$. The cleaning process stops when a clear herringbone reconstruction is observed with the STM [see Fig. 2(a)]. Next, germanium is evaporated from a graphite crucible using an electron-beam evaporator. The deposition and the subsequent annealing step are carried out in $2 \times 10^{-6}$ mbar pressure of oxygen. Remarkably, well-defined films are obtained at annealing temperatures $(\sim 580 \mathrm{~K})$ much lower than the one employed to grow germania films on $\mathrm{Ru}(0001)$ and on $\mathrm{Pt}(111)$ $(\sim 820 \mathrm{~K})[40,41]$. The amount evaporated onto the surface is inferred from previous experiments and based on the STM image features [40,41].

A germania bilayer film supported on $\mathrm{Au}(111)$ is shown in Fig. 1 . The film covers the total scanning area by $75 \%$, while the other 25\% [black in Figs. 1(a) and 1(b)] expose the gold surface, resulting in a coverage of 1.5 monolayers. The STM image in Fig. 1(c) has been taken in a small scanning area on one bilayer terrace. The film grows atomically flat and forms a 

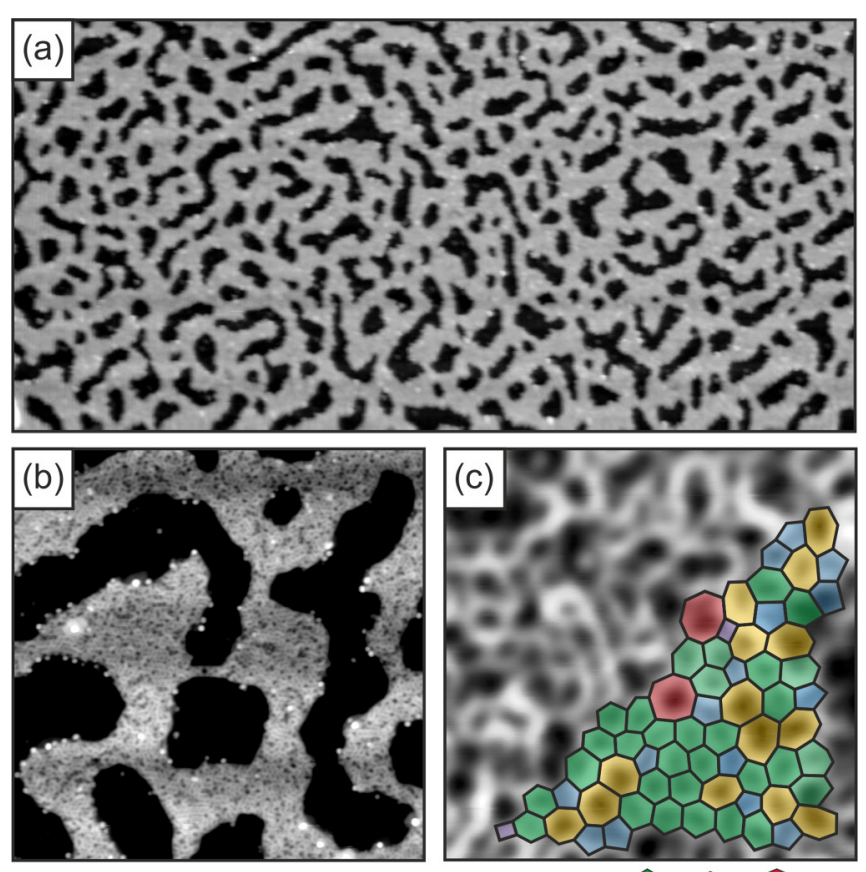

$4 \sqrt { 5 } 6 \longdiv { 7 } 8$

FIG. 1. STM images of a germania bilayer film supported on $\mathrm{Au}(111)$ of 1.5 monolayers of coverage. (a) $400.0 \mathrm{~nm} \times 200.0 \mathrm{~nm}$, $I_{T}=0.9 \mathrm{nA}, V_{S}=1.1 \mathrm{~V}$. (b) $70.0 \mathrm{~nm} \times 70.0 \mathrm{~nm}, I_{T}=0.3 \mathrm{nA}$, $V_{S}=0.7 \mathrm{~V}$. (c) Close-up view of a germania bilayer film terrace, where the observed ring sizes, indicated in color code below the figure, have been superimposed onto part of the STM topographic image. $8.0 \mathrm{~nm} \times 8.0 \mathrm{~nm}, I_{T}=0.2 \mathrm{nA}, V_{S}=0.15 \mathrm{~V}$.

number of different ring sizes that are color-coded accordingly in Fig. 1(c). A ring-size distribution from 4- to 8-membered rings is observed. One can note in Fig. 1(c) that the presence of three 6-membered rings sharing the same vertex is a preferred triplet combination. Additionally, in Fig. 1(b) areas with agglomerations of 6-membered rings can be observed. This is also observed in amorphous silica bilayer films supported on $\mathrm{Ru}(0001)$ [42]. However, the $(6,6,6)$ triplet combination is very scarce in amorphous germania bilayer films on $\operatorname{Pt}(111)$, whose crystalline phase is formed by 8 - and 5-membered rings [40]. In any case, due to the close similarity of the present film with this latter, we assume that the germania film on $\mathrm{Au}(111)$ grows in the same fashion, displaying a bilayer configuration, as we rationalize below.

In Fig. 2(b) we show another film prepared by depositing half of the amount of Ge (and keeping the other preparation conditions unchanged) with respect to the preparation of the film shown in Fig. 1. The area covered by the film is half of the one discussed above, suggesting once again the formation of a bilayer film. The film of coverage 0.6 monolayers [Fig. 2(b)] is characterized by small islands that are connected to each other by narrow stripes.

There are many similarities between the currently presented germania films on $\mathrm{Au}(111)$ and the previously reported silica films on $\mathrm{Pt}(111)$ [43], that are described next. In a range of coverages up to 2 monolayers, only bilayer films have been observed so far. Even after evaporation of small amounts of $\mathrm{Si}$ on $\mathrm{Pt}(111)$ and of $\mathrm{Ge}$ on $\mathrm{Au}(111)$ no monolayers are formed. Moreover, in both cases, the bilayer films are amorphous [43]. Silica bilayer films on $\operatorname{Pt}(111)$ of low coverage also exhibit islands bridged by narrow stripes. Unlike the germania films, the silica stripes follow the main crystallographic orientations of the $\operatorname{Pt}(111)$.

We have observed a bias dependency of the apparent height of the germania bilayer with respect to the bare gold. At a bias of $200 \mathrm{mV}$ we measure a thickness of the film of $\sim 0.20 \mathrm{~nm}$ and increases to $\sim 0.35 \mathrm{~nm}$ at $1.5 \mathrm{~V}$. In both cases the apparent heights are lower than the expected geometrical thickness for a germania bilayer $(\sim 0.48 \mathrm{~nm}$ plus $\sim 0.30 \mathrm{~nm}$ of the interfacial distance). A similar underestimation of the STM
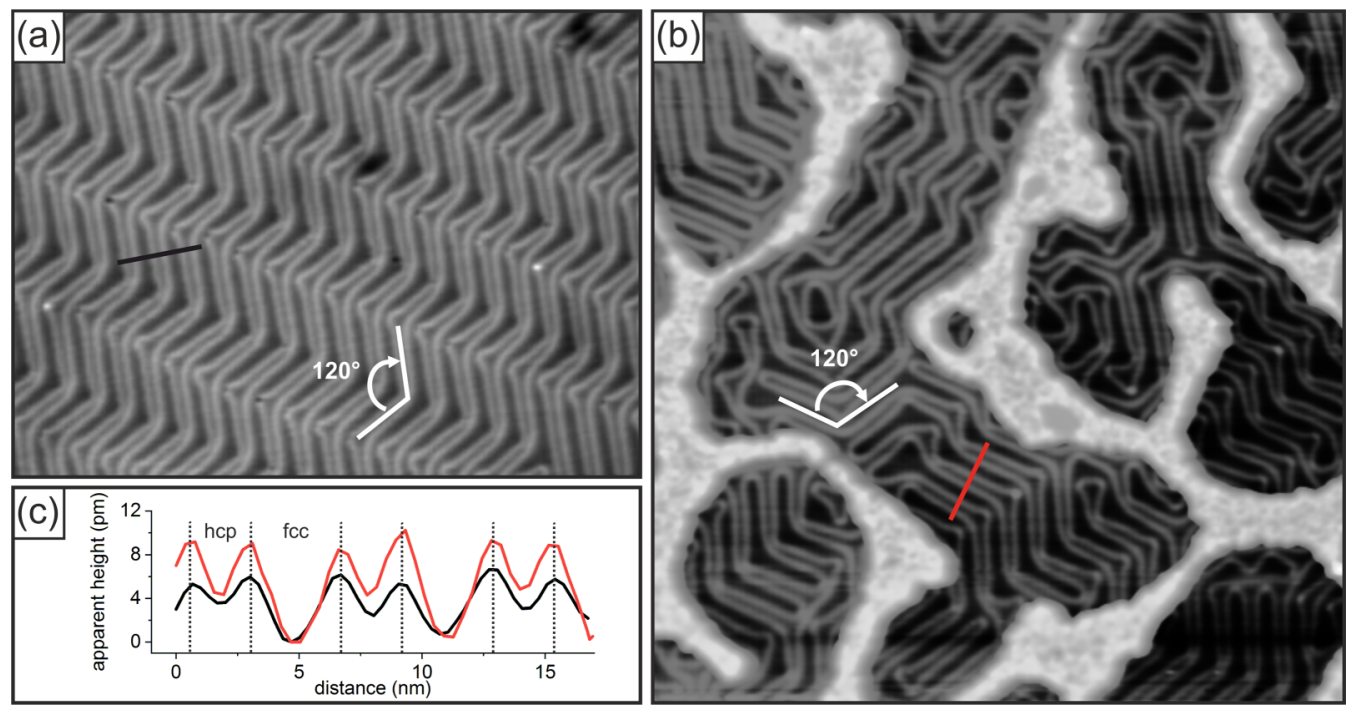

FIG. 2. Comparison of the $\mathrm{Au}(111)$ reconstruction in a bare single crystal and upon preparation of a metal-supported germania bilayer film. (a) STM image of bare reconstructed $\mathrm{Au}(111), 150.0 \mathrm{~nm} \times 100.0 \mathrm{~nm}, I_{T}=0.4 \mathrm{nA}, V_{S}=0.6 \mathrm{~V}$. (b) STM image of a low coverage germania bilayer film on reconstructed $\mathrm{Au}(111), 170.0 \mathrm{~nm} \times 170.0 \mathrm{~nm}, I_{T}=0.3 \mathrm{nA}, V_{S}=1.2 \mathrm{~V}$. (c) $\mathrm{STM} z$ profiles along the black line in (a) and the red line in (b). 

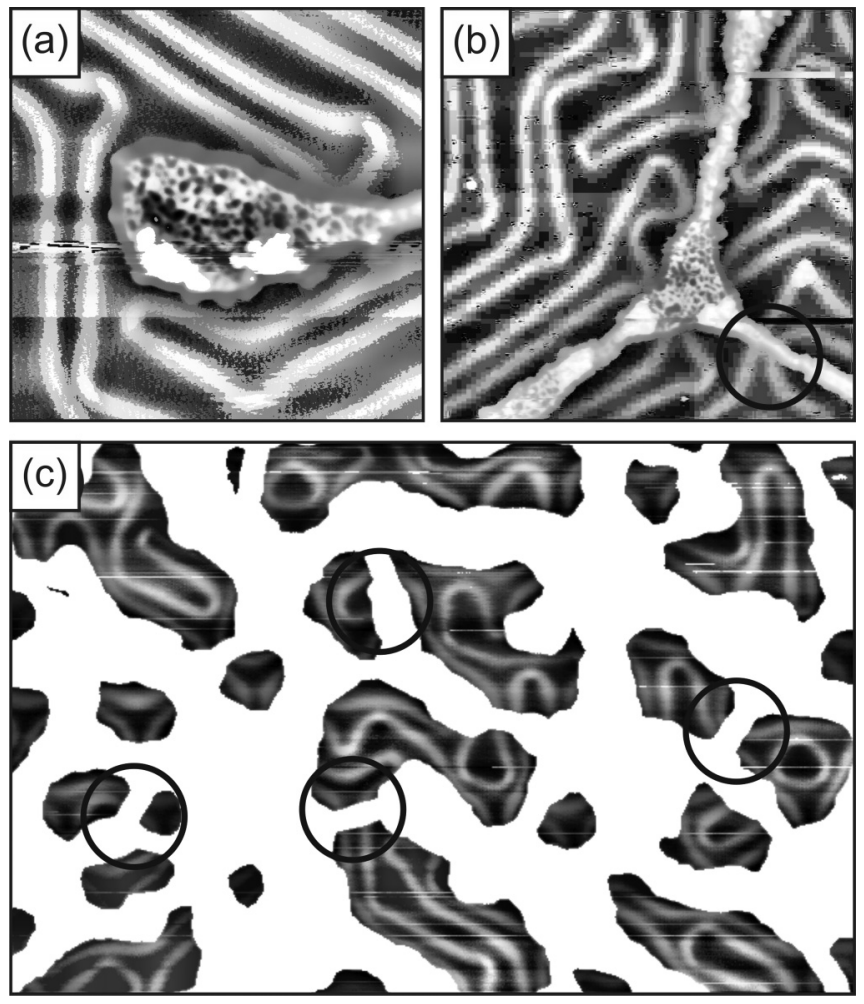

FIG. 3. Analysis of the Au soliton walls behavior due to the presence of the germania bilayer film. The contrast of the STM images has been enhanced for better visualization of the $\mathrm{Au}(111)$ support. Black circles mark areas where the Au soliton walls continue under the film. (a) $25.0 \mathrm{~nm} \times 25.0 \mathrm{~nm}, I_{T}=0.5 \mathrm{nA}, V_{S}=$ $1.8 \mathrm{~V}$. (b) $35.0 \mathrm{~nm} \times 35.0 \mathrm{~nm}, I_{T}=0.6 \mathrm{nA}, V_{S}=2.3 \mathrm{~V}$. (c) $100.0 \mathrm{~nm}$ $\times 65.0 \mathrm{~nm}, I_{T}=0.2 \mathrm{nA}, V_{S}=1.2 \mathrm{~V}$.

measured thickness of the film has been observed in silica bilayer films on $\operatorname{Pt}(111)$ [43]. In both systems this difference is assigned to electronic effects typically observed in metal supported oxides $[32,44]$.

The contrast of the STM image in Fig. 2(b) is tuned with the adaptive nonlinear color mapping mode available in the scanning probe microscopy data visualizer Gwyddion [45] so that one can simultaneously observe features of the bilayer and of the $\mathrm{Au}(111)$ reconstruction. Interestingly, by comparison with the pristine herringbone $\mathrm{Au}(111)$ [Fig. 2(a)], one can see that the gold reconstruction is disturbed by the presence of the film [Fig. 2(b)]. The herringbone reconstruction no longer has the long-range order and periodicity as in the bare substrate and the soliton walls form more complex patterns. However, some small areas between the film islands keep the same herringbone configuration as in the clean $\mathrm{Au}(111)$. The rotational angle of the domains is still $120^{\circ}$, as is shown with markers in Figs. 2(a) and 2(b). In addition, Fig. 2(c) exhibits STM profile lines taken along the black line in Fig. 2(a), and the red line in Fig. 2(b). The $z$-profile lines are perpendicular to the direction of the soliton walls. The agreement in the distance of $\sim 6.3 \mathrm{~nm}$ between the soliton walls in both systems manifests that the distance between double rows is unaltered.

STM images of different germania bilayer film preparations are depicted in Fig. 3. The STM images have been locally equalized in order to better visualize the $\mathrm{Au}(111)$ reconstruction. In Fig. 3(a) the herringbone reconstruction surrounding a germania bilayer island is affected in such a way that the soliton walls avoid the unreconstructed $\mathrm{Au}(111)$ surface underneath the film. Similar behavior has been observed for annealed islands of fullerenes and for $\mathrm{MoO}_{3}$ monolayer films on the same substrate [21,35]. However, it is also noted that some soliton walls continue under the bilayer film, as it is shown in the area enclosed by the black circles in Figs. 3(b) and 3(c). Thus, the interaction between the film and the $\mathrm{Au}(111)$ support is such that the herringbone reconstruction is partly lifted and partly remains under the film.

Further, we have investigated these film characteristics using DFT calculations [46,47]. However, given that the $(22 \times$ $\sqrt{3})$ periodicity typically observed in reconstructed $\mathrm{Au}(111)$ leads to unfeasible calculations, we hereby adopt a modeling strategy discussed in a previous paper [38], namely, we first relax the $\mathrm{Au}$ bulk lattice constant and cut a five-layers-thick slab along the (111) surface; subsequently, the ionic position of the three upper layers is relaxed, keeping the two bottom ones fixed at bulk lattice positions. Finally, a model for the hcp region is created by inducing a $3 \%$ compression of the surface interatomic distances while keeping the interlayer distance fixed. We adopt a PBE+D2' functional, yielding a lattice parameter of $\mathrm{Au}$ equal to $0.412 \mathrm{~nm}$ (close to the x-ray diffraction value of $0.408 \mathrm{~nm}$ [48]), corresponding to a surface interatomic distance of $0.291 \mathrm{~nm}$. Upon $3 \%$ compression, the interatomic distance reduces to $0.282 \mathrm{~nm}$. It is worth noting that the two surface regions display slightly different work functions, 5.13 and $5.24 \mathrm{eV}$ for the fcc and hcp models, respectively, which compares well with the literature values [49]. An intrinsic limit of this approach, consisting of separate simulations of the fcc and hcp domains, is that the ridges characterizing the herringbone reconstruction are not explicitly included in the models. It is therefore not possible to directly observe their lifting as seen in the experiments, while considerations regarding the nature and the strength of the film-substrate interactions can be done by comparison to similar computational studies. More computational details and the relaxed atomic coordinates for the fcc and hcp systems can be found in the Supplemental Material [50].

In the previously studied cases of hexagonal germania bilayer deposition on $\mathrm{Ru}(0001)$ and $\mathrm{Pt}(111)$, a simple coincidence of a $(1 \times 1)$ film cell on a $(2 \times 2)$ substrate cell led to an acceptable strain $[40,41]$. This is not the case for $\mathrm{GeO}_{2} / \mathrm{Au}$, where such a coincidence displays a tensile strain as large as $6 \%$ and $3 \%$ for the fcc and hcp $\mathrm{Au}(111)$ regions, respectively. We therefore create models displaying a convenient moiré pattern in order to accommodate the germania film on the gold substrate with a reasonably small lattice mismatch. For the fcc domain a $(3 \times 3)$ germania cell is put on a $(\sqrt{31} \times \sqrt{31}) \mathrm{Au}$ supercell with a rotation of $9^{\circ}$ (depicted in Fig. 4). For the hcp domain, $\mathrm{a}(4 \times 4) \mathrm{GeO}_{2}$ cell is put on $\mathrm{a}(\sqrt{61} \times \sqrt{61}) \mathrm{Au}$ supercell with a rotation of $26^{\circ}$.

The calculation results using this approach can be found in Table I, where the strain, the adhesion energy $\left(E_{a d}\right)$, the average interface distance $(d)$, the amount of electronic charge transferred to the film for surface unit $(Q)$, and the work function change with respect to the bare metal surface $(\Delta \Phi)$ are reported for both the fcc and hcp regions of $\mathrm{Au}(111)$. 


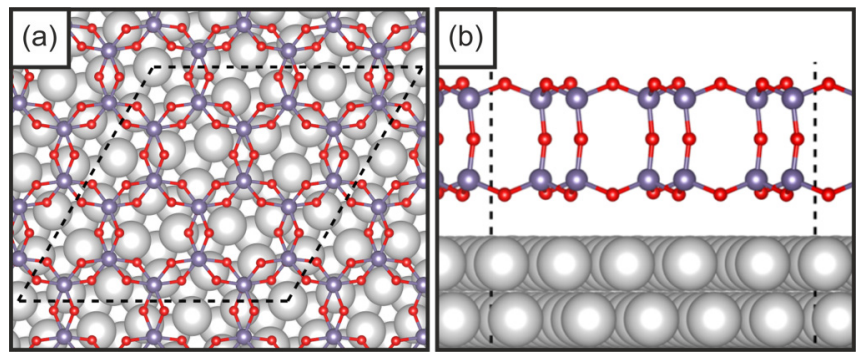

FIG. 4. Most stable DFT optimized geometry for a germania bilayer film supported on a fcc $\mathrm{Au}(111)$ domain. The unit cell is marked with dashed lines in both the top (a) and the side (b) view.

Additionally, for comparison, the table shows the adhesion properties for germania and silica bilayer films on $\mathrm{Ru}(0001)$ and $\mathrm{Pt}(111), \mathrm{NaCl}$ bilayer films on $\mathrm{Au}(111)$, and $\mathrm{MgO}$ bilayer films on $\mathrm{Ag}(100)$. The phases hex and 558 correspond to the formation of a network of 6-membered rings or a combination of 5- and 8-membered rings [40]. All the data have been obtained using the same computational approach, $\mathrm{PBE}+\mathrm{D} 2$ '. The adhesion energy is defined as [40]

$$
E_{a d}=\left[E\left(X A_{n} / M\right)-E\left(X A_{n}\right)-E(M)\right] / S,
$$

where $E$ is the total electronic energy of the $X A_{n} / M$ supported film, the freestanding film, and the metal support, respectively. $X=\mathrm{Ge}, \mathrm{Si}, \mathrm{Na}$, or $\mathrm{Mg} ; A=\mathrm{O}$ or $\mathrm{Cl} ; n=1$ or $2 ; M=\mathrm{Ru}, \mathrm{Pt}$, $\mathrm{Au}$, or $\mathrm{Ag}$, and $S$ is the supercell area.

The adhesion energy on the fcc domain is very small $\left(-1.54 \mathrm{eV} / \mathrm{nm}^{2}\right)$. On the hcp domain, a slightly larger value is reported $\left(-1.75 \mathrm{eV} / \mathrm{nm}^{2}\right)$. Both values are significantly smaller than the adhesion energy calculated for the hexagonal germania bilayer films on $\mathrm{Pt}(111)$ and $\mathrm{Ru}(0001)$ $\left(-2.20 \mathrm{eV} / \mathrm{nm}^{2}\right.$ and $-6.78 \mathrm{eV} / \mathrm{nm}^{2}$, respectively). Moreover, the mean interlayer distance is larger for the hexagonal film on $\operatorname{Au}(111)(0.301 \mathrm{~nm})$, than on $\operatorname{Pt}(111)(0.288 \mathrm{~nm})$ and on $\mathrm{Ru}(0001)(0.217 \mathrm{~nm})$. The mentioned calculated adhesion parameters are in line with the fact that germania supported on $\mathrm{Au}(111)$ forms pure amorphous bilayer films, while on
$\mathrm{Ru}(0001)$ and $\operatorname{Pt}(111)$ the observed structures are influenced by the presence of the metal support [40,41]. Moreover, a bilayer film of $\mathrm{MgO}$, a typical ionic oxide, is bound three times stronger to the $\operatorname{Ag}(001)$ substrate [51] than the germania film to the $\mathrm{Au}(111)$.

Notably, the system $\mathrm{NaCl} / \mathrm{Au}(111)$ [51], an example of an ideal physisorbed film, presents adhesion properties similar to $\mathrm{GeO}_{2} / \mathrm{Au}(111)$. Additionally, similar values are observed for the hexagonal film of $\mathrm{SiO}_{2} / \mathrm{Pt}(111)$, in agreement with the structural similarities, discussed above.

These experimental and DFT results contribute to the understanding of the role of the metal support in the oxide film structure. For instance, ultrathin films of silica (a material structurally analogous to germania) are significantly altered by the nature of the metal support. More specifically, the oxygen adsorption energy of the metal substrate may determine the structure of the silica film [43]. On high oxygen affinity metal substrates, such as Mo, silica forms only chemically bonded monolayer films [52]; on inert metals, such as Pd and $\mathrm{Pt}$, the film-substrate interaction is weaker and forms amorphous decoupled (or crystalline and nonconmensurate) bilayer films [43,53-55]; and on intermediate metal supports, such as $\mathrm{Ru}$, exhibits both types of behaviors [56-58]. Jhang et al. has shown by doping the silica films that the structure of the film is also heavily affected by the strain and charge transfer with the metal substrate [53]. Interestingly, silica bilayer films interact only through van der Waals forces with the metal substrate, as was determined by infrared reflection absorption spectroscopy and DFT calculations [58]. In fact, the weak coupling to the substrate is responsible for the randomly oriented unit blocks of $\mathrm{SiO}_{4}$ that give rise to amorphous networks. In our recently reported ultrathin germania films on $\mathrm{Ru}(0001)$ and $\mathrm{Pt}(111)$, we observe a similar correlation between the atomic structure of the film and the metal support to the one in the silica films [39-41]. While on $\mathrm{Ru}(0001)$ germania forms very stable hexagonal monolayer films [39] and ill-defined bilayer films [40], on $\mathrm{Pt}(111)$ forms a wide range of structures: monolayer films, crystalline and amorphous bilayer films [41], and a zigzag-line phase (comparable to the silica one [59]). On

TABLE I. Comparison of adhesion properties of metal-supported bilayer films calculated at the PBE+D2' level: strain, adhesion energy $\left(E_{a d}, \mathrm{eV} / \mathrm{nm}^{2}\right)$, average interface distance $(d, \mathrm{~nm})$, charge transferred to the film normalized per surface unit $\left(Q,|e| / \mathrm{nm}^{2}\right)$, and the work function change with respect to the bare metal surface $(\Delta \Phi, \mathrm{eV})$.

\begin{tabular}{|c|c|c|c|c|c|c|c|c|c|}
\hline System & Support & Phase & Coincidence & Strain $(\%)$ & $E_{a d}\left(\mathrm{eV} / \mathrm{nm}^{2}\right)$ & $d(\mathrm{~nm})$ & $Q\left(|e| / \mathrm{nm}^{2}\right)$ & $\Delta \Phi(\mathrm{eV})$ & Ref. \\
\hline \multirow[t]{4}{*}{$\mathrm{GeO}_{2}$} & $\mathrm{Ru}(0001)$ & hex & $(1 \times 1) /(2 \times 2)$ & +0.24 & -6.78 & 0.217 & 0.60 & +1.12 & [41] \\
\hline & & 558 & $(2 \times 3) /(\sqrt{67} \times \sqrt{147}) \mathrm{R} 12^{\circ}$ & $+1.7,+3.0$ & -7.46 & 0.219 & 2.10 & +0.57 & [40] \\
\hline & & 558 & $(2 \times 3) /(\sqrt{67} \times \sqrt{147}) \mathrm{R} 12^{\circ}$ & $+0.12,-1.23$ & -2.71 & 0.258 & 0.66 & +0.32 & [40] \\
\hline & $\mathrm{Au}(111)$ & hex (fcc) & $(3 \times 3) /(\sqrt{31} \times \sqrt{31}) \mathrm{R} 9^{\circ}$ & -1.26 & -1.54 & 0.301 & 0.35 & +0.17 & \\
\hline \multirow{3}{*}{$\mathrm{SiO}_{2}$} & & 558 & $(2 \times 3) /(\sqrt{67} \times \sqrt{147}) \mathrm{R} 12^{\circ}$ & $+5.76,+4.57$ & -1.13 & 0.263 & 0.79 & -0.73 & [40] \\
\hline & $\operatorname{Pt}(111)$ & hex & $(1 \times 1) /(2 \times 2)$ & +4.56 & -1.34 & 0.319 & 0.04 & -0.04 & [40] \\
\hline & & 558 & $(2 \times 3) /(\sqrt{67} \times \sqrt{147}) \mathrm{R} 12^{\circ}$ & $+7.52,+6.34$ & -0.65 & 0.285 & 0.11 & -0.38 & [40] \\
\hline $\mathrm{NaCl}$ & $\mathrm{Au}(111)$ & fec & $(2 \times 2) /(3 \sqrt{3} \times 3 \sqrt{3})$ & $\sim 5^{\mathrm{a}}$ & -2.55 & 0.312 & & & [51] \\
\hline $\mathrm{MgO}$ & $\operatorname{Ag}(100)$ & & $(1 \times 1) /(1 \times 1)$ & -2.16 & -4.69 & 0.262 & & & [51] \\
\hline
\end{tabular}

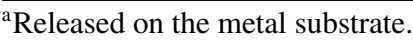


$\mathrm{Au}(111)$, a chemically inert surface, only amorphous bilayer films are observed, as expected for a film weakly coupled to the support.

To summarize, in contrast to earlier observations for oxide films on reconstructed $\mathrm{Au}(111)$ [32-35], several soliton walls penetrate below the germania bilayer film patches. This behavior indicates a weaker film-substrate interaction than the one observed for other oxide films. In other words, the changes in the soliton wall behavior of the $\mathrm{Au}(111)$ reconstruction upon film coverage yield a qualitative measure for the interaction strength. For the present ultrathin $\mathrm{GeO}_{2} / \mathrm{Au}(111)$ system, the consequence of the observed weak film-substrate interaction is an amorphous germania film growth. Our experiments and the theoretical modeling with
DFT calculations highlight quantitatively the impact of the metal support on the oxide film structure concerning strain, adhesion energy, charge transfer, and, most importantly in the present context, crystalline versus amorphous growth.

This project has received funding from the European Research Council (ERC) under the European Unions Horizon 2020 Research and Innovation Program (Grant Agreement No. 669179). S.T. and G.P. thank the Italian MIUR for financial support through the PRIN 2017 Project MULTI-e and CINECA for granting access to supercomputing resources via the ISCRA initiative. F.S. acknowledges the Alexander von Humboldt Foundation, MPG partner group program, FAPERJ, and CNPq grants.
[1] D. M. Zehner and J. F. Wendelken, Proceedings of the Seventh International Vacuum Congress and the Third International Conference on Solid Surfaces, Vienna, 1977 (unpublished).

[2] J. Perdereau, J. P. Biberian, and G. E. Rhead, J. Phys. F: Met. Phys. 4, 798 (1974).

[3] M. A. Van Hove, R. J. Koestner, P. C. Stair, J.-P. Bibérian, L. L. Kesmodel, I. Bartoš, and G. A. Somorjai, Surf. Sci. 103, 189 (1981).

[4] U. Harten, A. M. Lahee, J. P. Toennies, and C. Wöll, Phys. Rev. Lett. 54, 2619 (1985).

[5] S. Osella, D. Cornil, and J. Cornil, Phys. Chem. Chem. Phys. 16, 2866 (2014).

[6] J. V. Barth, H. Brune, G. Ertl, and R. J. Behm, Phys. Rev. B 42, 9307 (1990).

[7] W. Chen, V. Madhavan, T. Jamneala, and M. F. Crommie, Phys. Rev. Lett. 80, 1469 (1998).

[8] E. V. Iski, A. D. Jewell, H. L. Tierney, G. Kyriakou, and E. C. H. Sykes, J. Vac. Sci. Technol. A 29, 040601 (2011).

[9] M. Böhringer, K. Morgenstern, W.-D. Schneider, R. Berndt, F. Mauri, A. De Vita, and R. Car, Phys. Rev. Lett. 83, 324 (1999).

[10] C. Wagner, R. Franke, T. Dienel, R. Forker, R. Jacob, and T. Fritz, Appl. Phys. Lett. 91, 113111 (2007).

[11] S. Clair, S. Pons, A. P. Seitsonen, H. Brune, K. Kern, and J. V. Barth, J. Phys. Chem. B 108, 14585 (2004).

[12] A. Kirakosian, M. J. Comstock, J. Cho, and M. F. Crommie, Phys. Rev. B 71, 113409 (2005).

[13] B. A. Mantooth, E. C. H. Sykes, P. Han, A. M. Moore, Z. J. Donhauser, V. H. Crespi, and P. S. Weiss, J. Phys. Chem. C 111, 6167 (2007).

[14] C. B. France and B. A. Parkinson, Langmuir 20, 2713 (2004).

[15] C. B. France, P. G. Schroeder, J. C. Forsythe, and B. A. Parkinson, Langmuir 19, 1274 (2003).

[16] G. E. Poirier, Langmuir 13, 2019 (1997).

[17] P. Maksymovych, D. C. Sorescu, and J. T. Yates, Phys. Rev. Lett. 97, 146103 (2006).

[18] G. E. Poirier, Chem. Rev. 97, 1117 (1997).

[19] L. Huang, P. Zeppenfeld, J. Chevrier, and G. Comsa, Surf. Sci. 352-354, 285 (1996).

[20] B. K. Min, A. R. Alemozafar, M. M. Biener, J. Biener, and C. M. Friend, Top. Catal. 36, 77 (2005).

[21] E. I. Altman and R. J. Colton, Surf. Sci. 279, 49 (1992).
[22] X. Lu, M. Grobis, K. H. Khoo, S. G. Louie, and M. F. Crommie, Phys. Rev. B 70, 115418 (2004).

[23] M. Kiel, K. Duncker, C. Hagendorf, and W. Widdra, Phys. Rev. B 75, 195439 (2007).

[24] F. Rossel, P. Brodard, F. Patthey, N. V. Richardson, and W.-D. Schneider, Surf. Sci. 602, L115 (2008).

[25] J. K. Gimzewski, S. Modesti, C. Gerber, and R. R. Schlittler, Chem. Phys. Lett. 213, 401 (1993).

[26] F. Sellam, T. Schmitz-Hübsch, M. Toerker, S. Mannsfeld, H. Proehl, T. Fritz, K. Leo, C. Simpson, and K. Müllen, Surf. Sci. 478, 113 (2001).

[27] S. M. Driver, T. Zhang, and D. A. King, Angew. Chem., Int. Ed. 46, 700 (2007).

[28] D. O. Bellisario, A. D. Jewell, H. L. Tierney, A. E. Baber, and E. C. H. Sykes, J. Phys. Chem. C 114, 14583 (2010).

[29] A. D. Jewell, H. L. Tierney, and E. C. H. Sykes, Phys. Rev. B 82, 205401 (2010).

[30] C. $\mathrm{Wu}$ and M. R. Castell, Oxide Materials at the Two-Dimensional Limit (Springer, New York, 2016), pp. 149-168.

[31] Y. Pan, S. Benedetti, C. Noguera, L. Giordano, J. Goniakowski, and N. Nilius, J. Phys. Chem. C 116, 11126 (2012).

[32] C. Wu, M. S. J. Marshall, and M. R. Castell, J. Phys. Chem. C 115, 8643 (2011).

[33] D. Ragazzon, A. Schaefer, M. H. Farstad, L. E. Walle, P. Palmgren, A. Borg, P. Uvdal, and A. Sandell, Surf. Sci. 617, 211 (2013).

[34] F. Stavale, L. Pascua, N. Nilius, and H.-J. Freund, J. Phys. Chem. C 117, 10552 (2013).

[35] S. Y. Quek, M. M. Biener, J. Biener, C. M. Friend, and E. Kaxiras, Surf. Sci. 577, L71 (2005).

[36] S. Nie, N. C. Bartelt, J. M. Wofford, O. D. Dubon, K. F. McCarty, and K. Thürmer, Phys. Rev. B 85, 205406 (2012).

[37] F. Rossel, M. Pivetta, F. Patthey, E. Ćavar, A. P. Seitsonen, and W.-D. Schneider, Phys. Rev. B 84, 075426 (2011).

[38] K. Lauwaet, K. Schouteden, E. Janssens, C. Van Haesendonck, P. Lievens, M. I. Trioni, L. Giordano, and G. Pacchioni, Phys. Rev. B 85, 245440 (2012).

[39] A. L. Lewandowski, P. Schlexer, C. Büchner, E. M. Davis, H. Burrall, K. M. Burson, W.-D. Schneider, M. Heyde, G. Pacchioni, and H.-J. Freund, Phys. Rev. B 97, 115406 (2018). 
[40] A. L. Lewandowski, S. Tosoni, L. Gura, P. Schlexer, P. Marschalik, W.-D. Schneider, M. Heyde, G. Pacchioni, and H.-J. Freund, Angew. Chem., Int. Ed. 58, 10903 (2019).

[41] A. L. Lewandowski, P. Schlexer, S. Tosoni, L. Gura, P. Marschalik, C. Büchner, H. Burrall, K. M. Burson, W.-D. Schneider, G. Pacchioni, and M. Heyde, J. Phys. Chem. C 123, 7889 (2019).

[42] C. Büchner, L. Liu, S. Stuckenholz, K. M. Burson, L. Lichtenstein, M. Heyde, H.-J. Gao, and H.-J. Freund, J. NonCryst. Solids 435, 40 (2016).

[43] X. Yu, B. Yang, J. A. Boscoboinik, S. Shaikhutdinov, and H.-J. Freund, Appl. Phys. Lett. 100, 151608 (2012).

[44] U. Diebold, J. F. Anderson, K.-O. Ng, and D. Vanderbilt, Phys. Rev. Lett. 77, 1322 (1996).

[45] D. Nečas and P. Klapetek, Open Phys. 10, 181 (2012).

[46] G. Kresse and J. Furthmüller, Comput. Mater. Sci. 6, 15 (1996).

[47] G. Kresse and J. Furthmüller, Phys. Rev. B 54, 11169 (1996).

[48] T. B. Massalski, J. L. Murray, L. H. Bennet, and H. Baker, Binary Alloy Phase Diagrams (ASM International, Ohio, 1986), p. 1.

[49] T. Andreev, I. Barke, and H. Hövel, Phys. Rev. B 70, 205426 (2004).

[50] See Supplemental Material at http://link.aps.org/supplemental/ 10.1103/PhysRevB.100.241403 for computational details and relaxed atomic coordinates of the germania film system.

[51] H.-Y. T. Chen and G. Pacchioni, Phys. Chem. Chem. Phys. 16, 21838 (2014).
[52] J. Weissenrieder, S. Kaya, J.-L. Lu, H.-J. Gao, S. Shaikhutdinov, H.-J. Freund, M. Sierka, T. K. Todorova, and J. Sauer, Phys. Rev. Lett. 95, 076103 (2005).

[53] J.-H. Jhang, C. Zhou, O. E. Dagdeviren, G. S. Hutchings, U. D. Schwarz, and E. I. Altman, Phys. Chem. Chem. Phys. 19, 14001 (2017).

[54] H. Tissot, X. Weng, P. Schlexer, G. Pacchioni, S. Shaikhutdinov, and H.-J. Freund, Surf. Sci. 678, 118 (2018).

[55] E. I. Altman, J. Götzen, N. Samudrala, and U. D. Schwarz, J. Phys. Chem. C 117, 26144 (2013).

[56] B. Yang, W. E. Kaden, X. Yu, J. A. Boscoboinik, Y. Martynova, L. Lichtenstein, M. Heyde, M. Sterrer, R. Włodarczyk, and M. Sierka, Phys. Chem. Chem. Phys. 14, 11344 (2012).

[57] L. Lichtenstein, C. Büchner, B. Yang, S. Shaikhutdinov, M. Heyde, M. Sierka, R. Włodarczyk, J. Sauer, and H.-J. Freund, Angew. Chem., Int. Ed. 51, 404 (2012).

[58] D. Löffler, J. J. Uhlrich, M. Baron, B. Yang, X. Yu, L. Lichtenstein, L. Heinke, C. Büchner, M. Heyde, S. Shaikhutdinov, H.-J. Freund, R. Włodarczyk, M. Sierka, and J. Sauer, Phys. Rev. Lett. 105, 146104 (2010).

[59] D. Kuhness, H. J. Yang, H. W. Klemm, M. Prieto, G. Peschel, A. Fuhrich, D. Menzel, T. Schmidt, X. Yu, S. Shaikhutdinov, A. L. Lewandowski, M. Heyde, A. Kelemen, R. Włodarczyk, D. Usvyat, M. Schütz, J. Sauer, and H.-J. Freund, J. Am. Chem. Soc. 140, 6164 (2018). 